\title{
Susceptibility to Amphetamine-Induced Locomotor Sensitization Is Modulated by Environmental Stimuli
}

\author{
Sabina Fraioli, M.Sc., Hans S. Crombag, M.A., Aldo Badiani, M.D., and Terry E. Robinson, Ph.D.
}

We have previously reported that intravenous (I.V.) administrations of $0.5-1.0 \mathrm{mg} / \mathrm{kg}$ of amphetamine in the absence of any environmental stimuli predictive of drug administration failed to induce psychomotor sensitization whereas the same drug did produce robust sensitization when given in association with environmental novelty. These results were obtained by studying rotational behavior in animals with a unilateral 6-OHDA lesion of the mesostriatal dopamine system. The purpose of this study was to determine if environmental novelty has a similar effect on sensitization to the locomotor activating effects of amphetamine in neurologically intact rats. Rats were implanted with I.V. catheters and divided in four groups. Two groups were housed in locomotor activity cages and given seven consecutive I.V. infusions of either saline (SAL-HOME group) or $0.375 \mathrm{mg} / \mathrm{kg}$ of amphetamine (AMPH-HOME group), using a remotely activated delivery system. Simultaneously, the other two groups were transported to the test cages and given the same treatment (SAL-NOVEL and AMPH-NOVEL groups). After one week withdrawal, all groups were given an amphetamine challenge (0.375 mg/kg, I.V.). Amphetamine sensitization developed when the drug was administered under NOVEL conditions, as indicated by a progressive increase in ampheatmine-induced locomotor activity over test sessions and by a greater response to the amphetamine challenge in the AMPH-pretreated versus the SAL-pretreated group. In contrast, no sensitization was observed under HOME conditions. Similar results were obtained with the analysis of vertical activity. [Neuropsychopharmacology 20: 533-541, 1999] (c) 1999 American College of Neuropsychopharmacology. Published by Elsevier Science Inc.
KEY WORDS: Amphetamine; Sensitization; Environment; Novelty; Stress; Associative learning; Conditioning; Context; Locomotor activity; Rearing behavior; Rat

Repeated administration of psychostimulant drugs, such as amphetamine and cocaine, produces a progressive and persistent hypersensitivity to their behavioral activating effects (Robinson and Becker 1986; Stewart and Badiani 1993). It has been suggested that drug-

From the Department of Psychology, The University of Michigan, Ann Arbor, Michigan, (AB, HSC, TER), Istituto di Farmacologia Medica, University of Rome "La Sapienza," Rome, Italy (SF).

Address correspondence to: Aldo Badiani, Department of Psychology, The University of Michigan, 525 East University Street, Ann Arbor, MI 48109-1109.

Received May 13, 1998; revised July 10, 1998; accepted August 3, induced neuroadaptations responsible for behavioral sensitization may contribute to development of compulsive drug-seeking in addicts (Robinson and Berridge 1993) and to other psychiatric disorders (Robinson and Becker 1986; Segal and Schuckit 1983). The potential clinical implications of drug sensitization has led to considerable interest in factors that promote or hamper its development, including nonpharmacological factors.

Indeed, there is increasing evidence that both the development and the expression of behavioral sensitization can be powerfully modulated by nonpharmacological factors (for reviews, see Stewart and Badiani 1993; Robinson et al. 1998). For example, we have recently reported that environmental novelty can enhance the development of sensitization to the psychomotor activating effects of amphetamine and cocaine (Badiani et al. 
1995a-c; Badiani et al. 1997; Robinson et al. 1998). That is, the rate and the magnitude of behavioral sensitization are greater when these drugs are administered to rats immediately after they are placed in a novel test environment (group NOVEL), relative to when they are administered to rats that have been housed in the same environment for several days (group HOME). Furthermore, the differences between HOME and NOVEL groups are magnified by removing, in HOME animals, all environmental stimuli that usually accompany noncontingent drug administration, such as the presence of an experimenter in the testing room, the handling of the animals, and the needle prick associated with intraperitoneal (IP) injections (Crombag et al. 1996; Browman et al. 1998a, 1998b).

Most of our previous studies were conducted in rats with a unilateral 6-OHDA lesion of the mesostriatal dopamine system (although see Badiani et al. 1995a). In these animals, amphetamine elicits rotational behavior directed toward the side of the lesion, instead of locomotor activity and stereotyped behaviors, as in neurologically intact animals. We discussed elsewhere the advantages offered by the measure of rotational behavior over that of locomotor activity as an index of psychomotor activation (Badiani et al. 1995a, 1995c). However, it is important to establish whether the effect of environmental novelty on amphetamine sensitization described above is unique to rotational behavior in rats with a unilateral 6-OHDA lesion or whether it reflects a more general modulation of the psychomotor activating effects of amphetamine, such as locomotor activity in neurologically intact rats.

Thus, the purpose of this study was to compare the development of sensitization to amphetamine-induced locomotor activity in the presence of or in the absence of environmental stimuli associated with drug administration. To accomplish this, we modified our usual experimental procedure in two ways. First, we used a very low dose of amphetamine so that psychomotor sensitization would not result in a decrease of locomotor activity because of the emergence of stereotyped behavior (for a review, see Segal and Schuckit 1983). Second, we administered amphetamine to the NOVEL group after a period of habituation to the test environment, avoiding the possibility that the usually large unconditioned locomotor response to a novel test environment may mask the development of sensitization (for example, see Badiani et al. 1995a).

\section{METHODS}

\section{Subjects}

Male Sprague-Dawley rats (Harlan Sprague-Dawley Inc., Indianapolis, IN), weighing $250-275 \mathrm{~g}$ at the beginning of the experiment, were housed in stainless-steel hanging cages in a temperature- and humidity-controlled colony room (lights on from 6:00 to 8:00 P.M.). Food and water were available ad libitum. The animals were acclimatized to the colony room for 1 week before any experimental manipulation.

\section{Catheter Surgery}

In all rats, an intravenous catheter was inserted into their jugular vein using standard surgical techniques. The details concerning catheter construction and catheterization procedure have been described previously (Weeks 1972; Crombag et al. 1996). The main modification adopted in the present study was to secure the catheter to the skin between the shoulder blades using a tethering device similar to that described by Caine and colleagues (1993). At the end of the surgery, the catheter was filled with gentamicin solution $(50 \mathrm{mg} / \mathrm{ml})$ to prevent infections. Catheter patency was assessed at the end of the experiment by administering an intravenous (I.V.) infusion of $0.2 \mathrm{ml}$ thiopental solution. The data from rats that did not become ataxic within $5 \mathrm{~s}$ were excluded from the study.

\section{Apparatus}

The computerized apparatus used to measure locomotor activity and vertical activity (rearing behavior) has been described previously (Badiani et al. 1995c). Briefly, it included 10 ellipsoidal ( $45 \mathrm{~cm} \times 27 \mathrm{~cm}, 28 \mathrm{~cm}$ high) cages made of Plexiglas and equipped with two series of photosensitive devices. Two photobeams/photocells (placed on the long side of the cage $23.5 \mathrm{~cm}$ apart and $4.5 \mathrm{~cm}$ from the cage floor) were used for the measurement of locomotor activity (number of crossovers from one side of the cage to the other). Other four photobeams/photocells (two on the short side, $23 \mathrm{~cm}$ apart, and two on the long side, $38.5 \mathrm{~cm}$ apart; $13.5 \mathrm{~cm}$ from the cage floor) were used for the measurement of vertical activity (number of photocell counts).

\section{Testing Procedures}

After catheterization, the animals were divided into four groups: SAL-HOME $(N=4)$, SAL-NOVEL $(N=5)$, AMPH-HOME $(N=7)$, and AMPH-NOVEL $(N=5)$. All Ns refer to the numbers of animals included in the analysis of locomotor activity after successfully passing the catheter patency test. Due to the malfunctioning of some photocells, the data from two animals were excluded from the analysis of vertical activity.

Housing Conditions. Five days before beginning drug treatments, HOME animals were transported to a testing room where they were placed in the test cages described above and tethered via a flexible cable to a liq- 
uid swivel fixed to a counter-balanced arm suspended above the cage. HOME rats were left in these cages for the entire duration of the experiment (i.e., the test cages were also their "home"). Every morning (between 8:30 and 9:00 A.M.), the catheters were flushed with $50 \mu \mathrm{l}$ of sterile heparin solution and were connected to infusion lines filled with heparin solution. The infusion lines were connected via the liquid swivel to a syringe mounted on an electronic pump. At 2:00 P.M. HOME animals received an infusion of $70 \mu \mathrm{l}$ of heparin solution at a flow rate of $10 \mu \mathrm{l} / \mathrm{min}$ to habituate them to the noise of the electronic pumps and to the infusion procedures. At 6:00 P.M., the infusion lines were disconnected, and the catheters flushed with heparin solution. During this phase, the rats in the NOVEL groups were left in the main animal colony room, and their catheters were flushed twice a day with heparin using the same schedule as for HOME animals. This routine of catheter flushing was continued for the entire duration of the experiment in both the HOME and the NOVEL group.

Intermittent Drug Treatment. During the intermittent drug treatment phase the rats received seven consecutive daily I.V. administrations of $0.375 \mathrm{mg} / \mathrm{kg}$ amphetamine or of saline. This dose of amphetamine was selected because we previously determined that it is the lowest dose able to produce locomotor activity in NOVEL animals and half of the dose required to elicit stereotyped behavior. The treatments were administered at 11:00 A.M., 1:00 P.M., or 3:00 P.M. so that the animals could not establish an association between amphetamine administration and time of day.

The infusion was administered according to the following procedure. The distal portion of the infusion lines was filled with $15 \mu \mathrm{l}$ of amphetamine solution (AMPH-HOME) or saline (SAL-HOME). A tiny air bubble separated the treatment solution from the heparin solution that filled the remainder of the infusion line. Each infusion consisted of $30 \mu \mathrm{l}$ heparin solution (internal volume of the catheter), followed by $15 \mu \mathrm{l}$ of amphetamine or saline solution, and by an additional $25 \mu \mathrm{l}$ of heparin solution, for a total of $70 \mu \mathrm{l}$ delivered at a flow rate of $10 \mu \mathrm{l} / \mathrm{min}$. Thus, although the total infusion period was of $7 \mathrm{~min}$, the $15 \mu \mathrm{l}$ of amphetamine or saline solution was delivered over a period of $1.5 \mathrm{~min}$.

HOME animals were connected to the infusion lines in the morning after their catheter had been flushed (8:30-9:00 A.M.), but the infusion occurred only 2-6 h later, when the syringe pumps were activated by remote control (i.e., from outside the testing room). In contrast, the NOVEL rats were transported each day from the animal colony to a testing room and placed in locomotor activity cages identical to those in which HOME rats lived. HOME animals were then tethered and connected to an infusion line filled with either amphetamine (AMPH-NOVEL) or saline (SAL-NOVEL).
NOVEL animals were then left undisturbed in test environment for $30 \mathrm{~min}$ before each infusion to minimize the levels of spontaneous locomotor activity at the time of the drug treatment. That is, the syringe pumps were activated $25.5 \mathrm{~min}$ after the rats were placed in the test environment (see Figure 1). Each test session lasted 60 min, after which time NOVEL rats were returned to their hanging cages in the animal colony room.

Amphetamine and Saline Challenges. Following the last amphetamine or saline treatment, all animals were left undisturbed for 7 days, except for the husbandry routine, weighing procedures, and catheter flushing procedures. On the eighth day, all rats were administered an I.V. infusion of $0.375 \mathrm{mg} / \mathrm{kg}$ amphetamine (amphetamine challenge) to test for the expression of amphetamine sensitization, using the same treatment procedures described above. Twenty-four hours later, all rats received an infusion of saline (saline challenge) to test for the expression of a conditioned response to the infusion procedure.

\section{Drugs}

Before surgery, the animals received $0.2 \mathrm{mg} / \mathrm{kg}$ I.P. atropine methyl nitrate (Sigma Chemical Company, St. Louis, MO) dissolved $(0.5 \mathrm{mg} / \mathrm{ml})$ in saline. Surgical anesthesia was induced with $52 \mathrm{mg} / \mathrm{kg}$ I.P. pentobarbital sodium, dissolved $(64.8 \mathrm{mg} / \mathrm{ml})$ in a $10 \%$ ethanol solution (Nembutal, The Butler Company, Columbus, $\mathrm{OH})$, supplemented with methoxyflurane (Metofane, Mallikrody Veterinary, Mundelein, IL). Heparin (Sigma) was dissolved (30 USP $/ \mathrm{ml}$ ) in saline. Thiopental sodium was dissolved $(20 \mathrm{mg}$ in $1 \mathrm{ml})$ in deionized water (Pentothal, Abbott Laboratories, Chicago, IL). D-amphet-

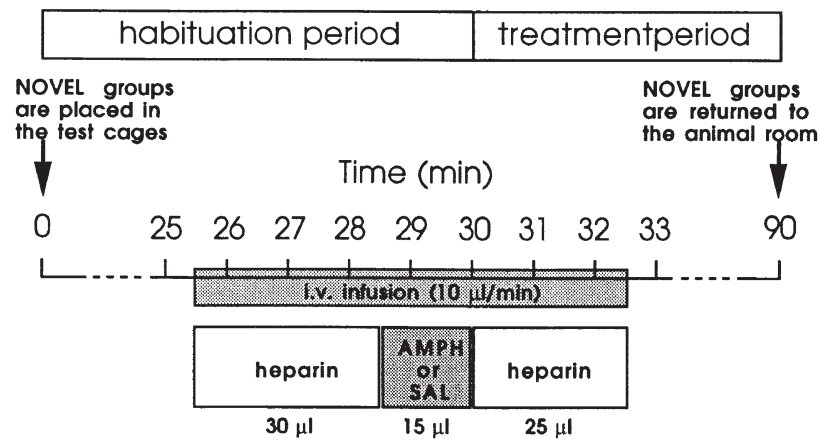

Figure 1. Each intravenous infusion consisted of $30 \mu l$ heparin solution (internal volume of the catheter), followed by $15 \mu \mathrm{l}$ of amphetamine or saline solution, and by an additional $25 \mu$ l of heparin solution, for a total of $70 \mu$ l delivered at a flow rate of $10 \mu \mathrm{l} / \mathrm{min}$. Thus, the $15 \mu \mathrm{l}$ of amphetamine or saline solution was delivered over a period of $1.5 \mathrm{~min}$. Notice that the syringe pumps for the NOVEL groups were activated $25.5 \mathrm{~min}$ after the rats were placed in the test environment. 
amine sulfate (Sigma) was dissolved $(0.375 \mathrm{mg} / \mathrm{ml})$ in saline. All drug weights refer to the weight of the salts. All solutions for intravenous administration were prepared with buffered saline $(0.9 \% \mathrm{NaCl})$ at $\mathrm{pH}$ 7.3.

\section{Data Analysis}

Differences between the AMPH-HOME and the AMPHNOVEL group on the first test session were assessed with a planned Student's t-test.

The data from the seven treatment sessions were analyzed with a two-way analysis of variance (ANOVA) with repeated measures (group, four levels: SALHOME, AMPH-HOME, SAL-NOVEL, and AMPHNOVEL; test session, seven levels).

Locomotor sensitization was assessed in two ways. First, we determined whether there was a progressive increase in amphetamine-induced locomotion over daily test sessions by performing linear regression analyses in each treatment group (see Badiani et al. 1995a). Second, we determined whether there were differences in drug effect between amphetamine-pretreated and saline-pretreated rats following 1 week withdrawal from the treatment (amphetamine challenge). The data from the amphetamine challenge and the saline challenge test were analyzed with two-way ANOVAs (pretreatment, two levels, SAL and AMPH; test environment, two levels).

Pair-wise comparisons were conducted with Fisher's PLSD posthoc tests.

The details of the statistical analyses are reported in the figure legends to make the Results section more readable.

\section{RESULTS}

\section{Locomotor Activity}

Figure 2 illustrates the time-course of locomotor activity before (0-30 $\mathrm{min}$; habituation) and after (30-90 $\mathrm{min}$; treatment) the first I.V. infusion of either saline (SALHOME and SAL-NOVEL groups) or $0.375 \mathrm{mg} / \mathrm{kg}$ amphetamine (AMPH-HOME and AMPH-NOVEL groups). It can be seen that baseline locomotor activity in both HOME groups was negligible (less than one crossover in $10 \mathrm{~min}$ ). Exposure to the novel test environment (NOVEL groups) produced a modest but significant increase in activity levels that declined over the $30 \mathrm{~min}$ of the habituation period. Amphetamine treatment elicited only a small, nonsignificant $(p=.087)$ increase in locomotor activity, confirming that this is a threshold dose for the induction of locomotor activity, with no significant differences between the AMPH-HOME and the AMPH-NOVEL groups.

When given repeatedly under NOVEL conditions, however, amphetamine began to produce a significant
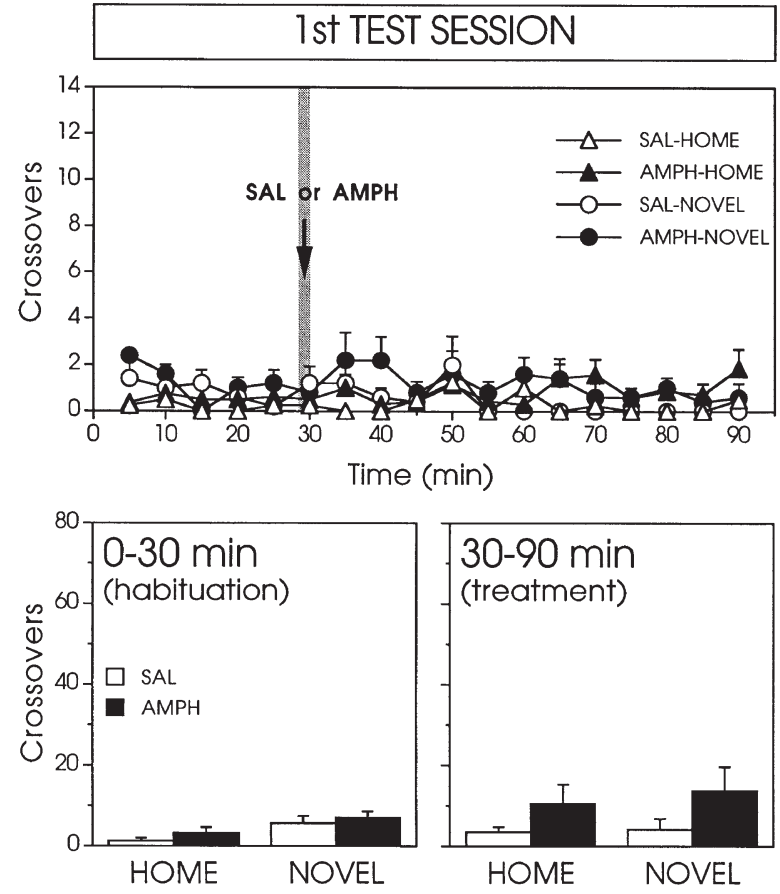

Figure 2. Time-course (5-min bins) of crossovers (means \pm SEs) before (0-30 $\mathrm{min}$; habituation) and after (30-90 min; treatment) the first I.V. infusion of either saline (SAL-HOME and SAL-NOVEL groups) or $0.375 \mathrm{mg} / \mathrm{kg}$ amphetamine (AMPHHOME and AMPH-NOVEL groups). A two-way ANOVA showed that during the habituation period there was a significant effect of environment $(F 1,17=5.55, p=.031)$, but no significant effect of treatment $(F 1,17=47.91, p=.25)$, nor an environment by treatment interaction $(F 1,17=0.11, p=.75)$. The two-way ANOVA on the data from the treatment period showed no significant effect of environment $(F 1,17=0.18$, $p=.67)$ and no environment by treatment interaction $(F 1,17=$ $0.08, p=.79)$; the effect of treatment approached significance $(F 1,17=3.29, p=.087)$.

increase in locomotor activity (see Figure 3B legend for statistics), and this effect became progressively larger with the repetition of the treatment (i.e., it sensitized), as indicated by a significant positive slope for the line of regression of crossovers over test sessions $(p=.033)$. When given under HOME conditions, amphetamine also produced a significant increase in locomotor activity over the saline group (see Figure 3B legend for statistics), but this effect did not change over time (i.e., there was no sensitization).

Locomotor activity during the habituation period (Figure 3A) was significantly higher in the two NOVEL groups than in the two HOME groups. However, the AMPH-NOVEL group was significantly more active than the SAL-NOVEL group ( $p=.05)$, possibly because of the development of a conditioned response to the test environment.

Figure 4 (amphetamine challenge) shows the time course of locomotor activity before and after a challenge 

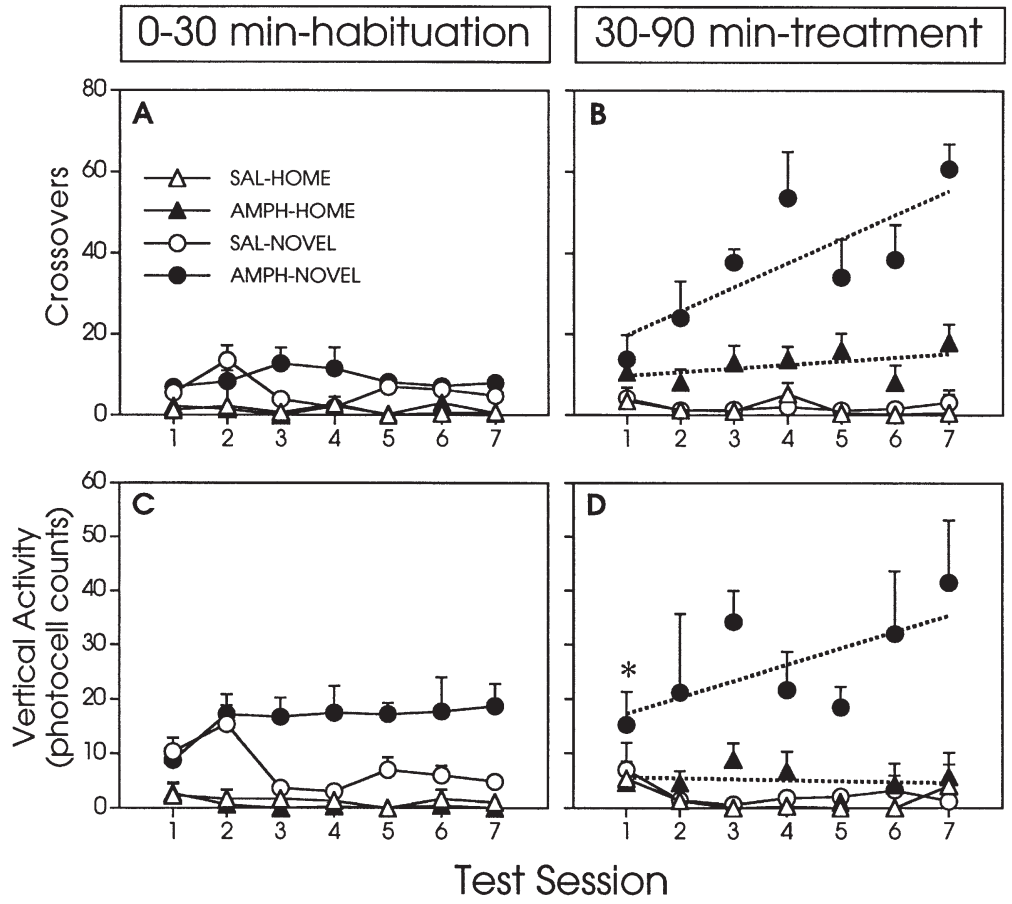

Figure 3. Mean number ( \pm SEM) of crossovers (A and B) and vertical activity counts counts (C and D) before (0-30 min; habituation) and after (30-90 min; treatment) seven concecutive daily I.V. infusions of either saline (SAL-HOME and SAL-NOVEL groups) or $0.375 \mathrm{mg} / \mathrm{kg}$ amphetamine (AMPH-HOME and AMPH-NOVEL groups). (A): A two-way ANOVA with repeated measures showed a significant effect of group $(F 3,17=20.02, p<.0001)$ but no effect of test session $(F 6,102=1.13, p=.35)$, nor environment by test session interaction $(F 18,102=1.54, p=.091)$. Posthoc Fisher PLSD tests indicated significant differences $(p s \leqslant .001)$ between the NOVEL groups and both HOME groups, and between the AMPH-NOVEL group and the SAL-NOVEL group $(p=.033)$. (B): A two-way ANOVA with repeated measures showed a significant effect of group $(F 3,17=95.79, p<$ $.0001)$ and test session $(F 6,102=3.78, p=.002)$, and an environment by test session interaction $(F 18,102=2.28, p=.005)$. Posthoc Fisher PLSD tests indicated significant differences $(p s \leqslant .001)$ between the AMPH groups and both SAL groups and between the AMPH-NOVEL group and the AMPH-HOME group $(p<.0001)$. Regression analyses showed a significant positive slope for the regression of number crossovers over test session (i.e., sensitization) in the AMPH-NOVEL $\left(r^{2}=.63, p=.033\right)$ but not in the AMPH-HOME group $\left(r^{2}=.26, p=.24\right)$. (C): A two-way ANOVA with repeated measures showed a significant effect of group $(F 3,14=39.83, p<.0001)$ but no effect of test session $(F 6,84=1.34, p=.24)$; there was an environment by test session interaction $(F 18,84=2.06, p=.014)$. Posthoc Fisher PLSD tests indicated significant differences $(p s \leqslant .01)$ between the NOVEL groups and both HOME groups, and between the AMPH-NOVEL group and the SAL-NOVEL group ( $p<.0001)$. (D): A two-way ANOVA with repeated measures showed a significant effect of group $(F 3,14=14.46, p<.0001)$ but no effect of test session $(F 6,84=3.78, p=.002)$, nor environment by test session interaction $(F 18,84=1.14, p=.14)$. Posthoc Fisher PLSD tests indicated significant differences $(p s \leqslant .001)$ between the AMPH-NOVEL group and all other groups $(p<.0001)$. Regression analyses showed a positive (although not significant) slope for the regression of number crossovers over test session in the AMPH-NOVEL $\left(r^{2}=.46, p=.095\right)$ but not in the AMPH-HOME group $\left(r^{2}=.025, p=.73\right)$. The asterisk refers to a one-tail Student $t$-test between the AMPH-HOME and the AMPH-NOVEL group.

infusion of $0.375 \mathrm{mg} / \mathrm{kg}$ amphetamine as a function of drug pretreatment (AMPH versus SAL) and of environmental condition (HOME versus NOVEL). Only animals in the NOVEL group sensitized, as indicated by significant differences between AMPH-pretreated and SAL-pretreated groups in the NOVEL $(p=.004)$ but not in the HOME condition $(p=.59)$. Furthermore, the pretreatment by environment interaction approached significance $(p=.069)$. Locomotor activity levels during the habituation period were similar to those observed on the seventh test session for all four groups, and again there was a significant difference between AMPH-NOVEL and SAL-NOVEL groups $(p=.025)$.
Figure 5 (saline challenge) shows the time course of locomotor activity activity before and after an infusion of saline given $24 \mathrm{~h}$ after the amphetamine challenge session. On this occasion, there were no significant differences between the AMPH-NOVEL and the SALNOVEL group during the habituation period, and there was no evidence of conditioned response to the infusion procedure in any group.

\section{Vertical Activity}

The analysis of vertical activity (Figure 3C,D; Figure 6) substantially confirmed the results obtained with the 

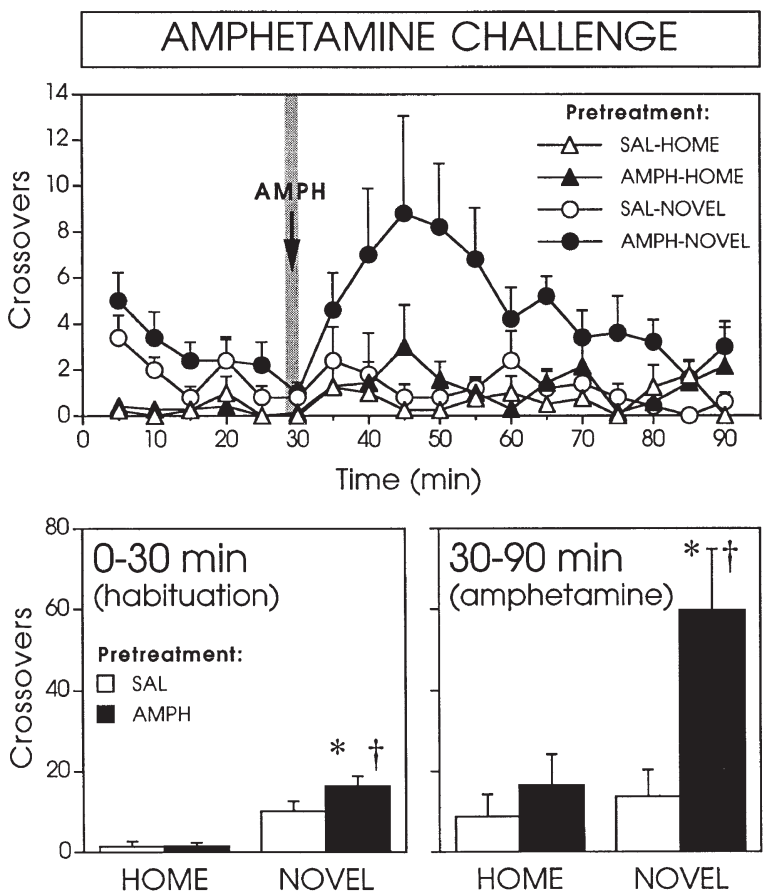

Figure 4. Time-course (5-min bins) of crossovers (means \pm SEs) before (0-30 min; habituation) and after (30-90 min; treatment) an I.V. infusion of $0.375 \mathrm{mg} / \mathrm{kg}$ amphetamine in animals that had received repeated infusions of either saline (SAL-pretreatement) or (AMPH-pretreatment) under either HOME or NOVEL conditions. A two-way ANOVA showed that during the habituation period there was a significant effect of environment $(F 1,17=43.85, p<.0001)$ but no effect of pretreatment $(F 1,17=3.11, p=.095)$, nor environment by treatment interaction $(F 1,17=2.97, p=.1)$. The two-way ANOVA on the data from the treatment period showed significant effect of environment $(F 1,17=5.99, p=.025)$ and pretreatment $(F 1,17=7.37, p=.015)$; the environment by pretreatment interaction approached significance $(F 1,17=$ 3.74, $p=.069$ ). Posthoc Fisher PLSD tests indicated significant differences between the AMPH-NOVEL and the AMPH-HOME group (asterisks, $p=.004$ ) and between the AMPH-NOVEL group and the SAL-NOVEL group (dagger, $p=.004)$.

analysis of locomotor activity. However, this time there was a significant difference between the AMPH-HOME and the AMPH-NOVEL group $(p=.048)$ on the first test session (Figure 3D).

Most importantly, sensitization of vertical activity also developed under NOVEL but not HOME conditions. Figure 3D shows that there was a positive, although not significant, slope for the line of regression of photocell counts over test sessions only in the AMPHNOVEL group $(p=.095)$. Furthermore, on the amphetamine challenge session (Figure 6), there were significant differences between AMPH-pretreated and SALpretreated groups in the NOVEL $(p=.002)$ but not in the HOME condition $(p=.81)$, and there was a pretreatment by environment interaction $(p=.014)$.
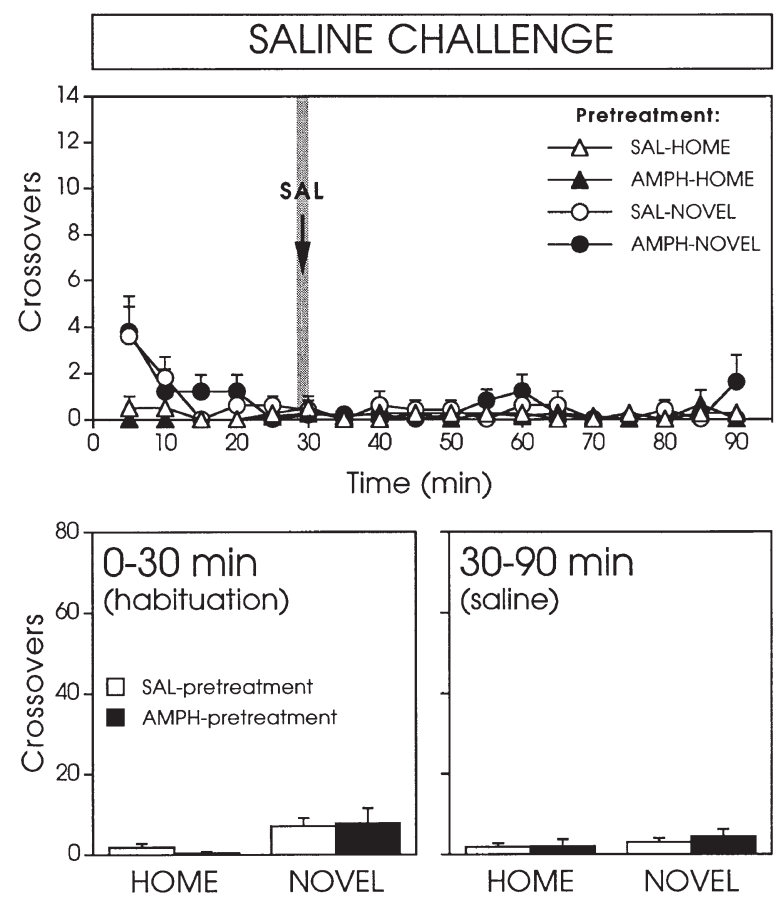

Figure 5. Time-course (5-min bins) of crossovers (means \pm SEs) before (0-30 min; habituation) and after (30-90 min; treatment) an I.V. infusion of saline in animals that had received repeated infusions of either saline (SAL-pretreatement) or $0.375 \mathrm{mg} / \mathrm{kg}$ amphetamine (AMPH-pretreatment) under either HOME or NOVEL conditions. A two-way ANOVA showed that during the habituation period there was a significant effect of environment $(F 1,17=8.04, p=$ $.011)$ but not of pretreatment $(F 1,17=0.03, p=.87)$, nor an environment by treatment interaction $(F 1,17=0.19, p=.67)$. The two-way ANOVA on the data from the treatment period showed no significant effect of environment $(F 1,17=0.93$, $p=.35)$ or pretreatment $(F 1,17=0.31, p=.59)$, nor environment by treatment interaction $(F 1,17=0.06, p=.81)$.

As with locomotor activity, on the saline challenge session, there were no differences between the AMPHNOVEL and SAL-NOVEL groups either before or after the saline infusion, and there was no evidence of conditioned response to the infusion procedure in any group (data not shown).

\section{DISCUSSION}

We reported previously that repeated intravenous administrations of moderate doses of amphetamine (0.5$1.0 \mathrm{mg} / \mathrm{kg}$ ) failed to induce sensitization of rotational behavior in rats with a unilateral 6-OHDA lesion of the mesostriatal dopamine system, when the drug was given at home in the absence of any environmental stimuli predictive of drug administration (Crombag et al. 1996; Browman et al. 1998b). In contrast, the same treatment produced robust sensitization when adminis- 

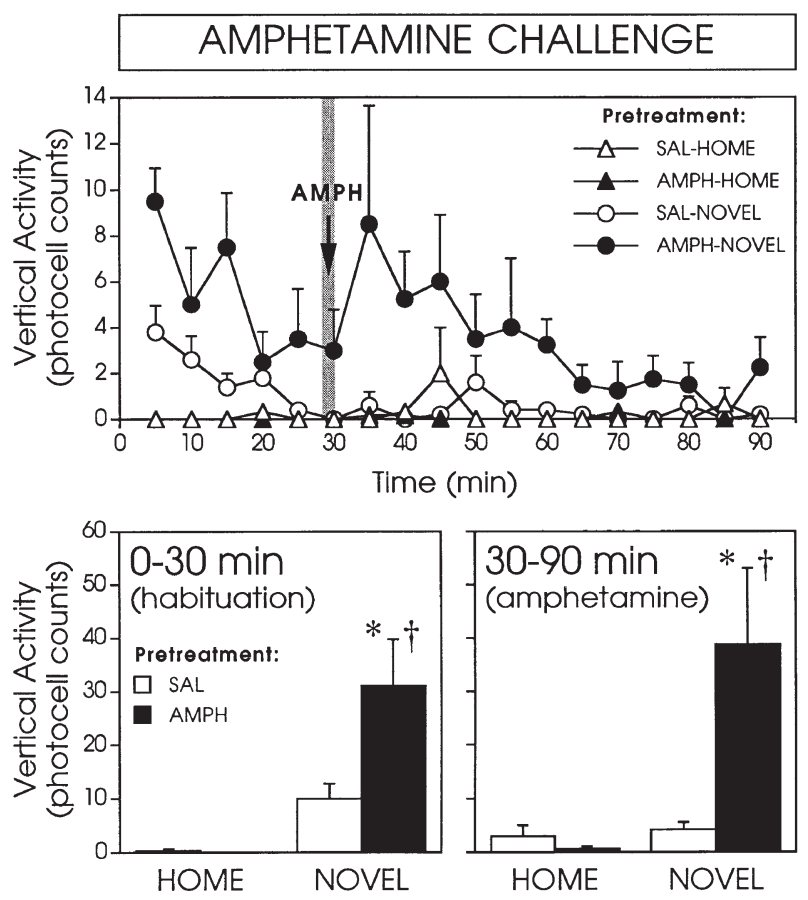

Figure 6. Time-course (5-min bins) of vertical activity photocell counts (means \pm SEs) during the amphetamine challenge session (see Figure 4). A two-way ANOVA showed that during the habituation period there was a significant effect of environment $(F 1,14=22.47, p=.0003)$ and pretreatment $(F 1,14=5.80, p=.030)$, and an environment by treatment interaction $(F 1,14=6.18, p=.026)$. The two-way ANOVA on the data from the treatment period showed significant effect of environment $(F 1,14=8.98, p=.01)$ and pretreatment $(F 1,14=6.04, p=.028)$ and an environment by pretreatment interaction $(F 1,14=7.91, p=.069)$. Posthoc Fisher PLSD tests indicated significant differences between the AMPH-NOVEL and the AMPH-HOME group (asterisks, $p<.001)$ and between the AMPH-NOVEL group and the SAL-NOVEL group (dagger, $p=.002$ ).

tered immediately after exposing the animals to a novel test environment. We report here that this effect of environmental novelty on the susceptibility to amphetamine sensitzation is not unique to rotational behavior or to animals with a unilateral 6-OHDA lesion. Neurologically intact rats that received repeated I.V. infusions of $0.375 \mathrm{mg} / \mathrm{kg}$ amphetamine in the absence of environmental stimuli predictive of drug administration did not develop behavioral sensitization to the locomotor activating effects of amphetamine. In contrast, animals that received the same amphetamine treatment after being placed in a relatively novel test environment did develop sensitization to amphetamine-induced locomotor activity and rearing.

In the present study, environmental novelty did not significantly affect the acute locomotor response to amphetamine, although it did enhance amphetamineinduced rearing behavior. Despite no effect of environ- mental condition on the acute locomotor response, there was a marked effect of environment on the development of locomotor sensitization. In previous studies (Badiani et al. 1995a, 1997; Crombag et al. 1996; Browman et al. 1998b), however, we have found that environmental novelty enhances both the acute rotational response to amphetamine and the development of sensitization to this effect. A number of procedural differences between these earlier experiments and the present study might explain why there was no effect of environment on the acute locomotor response to amphetamine in the present study. First, the dose of amphetamine used here was quite low $(0.375 \mathrm{mg} / \mathrm{kg}$ I.V.) and just at the threshold required to elicit locomotor activation. Thus, there may have been a "floor effect." Second, to control for the large unconditioned locomotor response produced by exposure to a novel environment, the animals in the NOVEL group were habituated for $30 \mathrm{~min}$ to the test environment before drug administration. This may have been sufficient to abolish the effect of environmental novelty on the acute locomotor response but not that on locomotor sensitization. However, it is important to emphasize that such a dissociation was not evident with the analysis of rearing behavior. Taken together, the present findings provide further evidence for the notion that the effect of environmental manipulations on the susceptibility to behavioral sensitization can be dissociated from their effect on acute drug responsiveness. We reported a similar phenomenon in an experiment using cocaine, in which there was no effect of environmental novelty on the acute response to cocaine, whereas there was a large effect on cocaine sensitization (Badiani et al. 1995b).

We have previously discussed (Badiani and Robinson 1994; Badiani et al. 1995a; Robinson et al. 1998) a number of possible explanations for the modulatory actions of environmental novelty on amphetamine sensitization. One hypothesis we have investigated in detail is based on the assumption that the development of sensitization depends on associative learning processes (Pert et al. 1990; Stewart 1992). The ability of drugpaired environmental stimuli to acquire conditioned stimulus properties, for example, might add a progressively larger conditioned response (CR) to the unconditioned drug effect. As illustrated in Figure 4 and 6, animals treated with amphetamine under NOVEL conditions did exhibit a psychomotor CR to the test environment. It is unlikely, however, that this CR could have contributed to the development of amphetamine sensitization in the AMPH-NOVEL group because the treatment occurred about $30 \mathrm{~min}$ after exposure to the test environment when the CR had almost completely subsided (see Figure 4, top panel). On the other hand, associative learning processes might have endowed the test environment with the ability to modify the psychomotor response to amphetamine independently of its ability to 
elicit a CR (for a discussion of this issue, see Anagnostaras and Robinson 1996; Stewart and Badiani 1993).

Alternatively, the action of the novel test environment as a stressor might have modulated the development of amphetamine sensitization independently of associative learning processes. Indeed, it is well known that environmental novelty can produce neuroendocrine and physiological changes usually associated with conditions of stress, such as activation of the hypothalamo-pituitary-adrenal axis and corticotrophin-releasing factor-dependent hypertension, tachicardia, and hyperthermia (Friedman and Ader 1967; Morimoto et al. 1993) and that these changes do not easily extinguish even after repeated exposure (Hennessy 1991). Repeated exposure to stressors has been shown to produce sensitization to the psychomotor activating effects of amphetamine (Antelman et al. 1980). Environmental novelty may have acted similarly to enhance amphetamine sensitization in the NOVEL group.

We do not know what neurobiological mechanisms are responsible for these effects of environmental novelty on the psychomotor activating effects of amphetamine. The behavioral activating effects of amphetamine are thought to depend on the ability of amphetamine to release dopamine in the terminal regions of the mesostriatal dopamine system, especially in the caudate and nucleus accumbens (Wise and Bozarth 1987; Le Moal 1995). In addition, amphetamine produces a cascade of postsynaptic changes that may be modulated independently of dopamine release, including the induction of immediate early genes such as c-fos in the medium spiny neurons of the striatal complex (Graybiel et al. 1990). We have demonstrated that environmental novelty has no effect on amphetamine pharmacokinetics (Badiani et al. 1997) or the ability of acute amphetamine to increase extracellular concentrations of dopamine either in the caudate or in the core or shell of the nucleus accumbens (Robinson and Badiani 1994). Thus, it appears that the ability of environmental novelty to enhance the psychomotor activating effects of amphetamine does not depend on a modulation of the primary neuropharmacological actions of this drug.

In contrast, we have found that environmental novelty can alter the ability of acute amphetamine to induce the expression of the immediate early gene c-fos in D1 and D2 receptor subpopulations of striatal neurons (Badiani et al. 1998). These findings suggest that the neural circuitry engaged by amphetamine varies as a function of the environment in which the drug is administered. Furthermore, since c-fos is a transcription factor implicated in the regulation of other genes, changes in its regulation may result in long-lasting neuroadaptations in the neural systems that mediate amphetamine actions. We are currently investigating whether amphetamine sensitization is accompanied by enduring changes in the expression of intermediate early genes.

\section{ACKNOWLEDGMENTS}

We thank P. Nencini for his comments on a previous version of this manuscript. This study was supported by a grant from the National Institute on Drug Abuse (DA04294).

\section{REFERENCES}

Anagnostaras SG, Robinson TE (1996): Sensitization to the psychomotor stimulant effects of amphetamine: modulation by associative learning. Behav Neurosci 110: 1397-1414

Antelman SM, Eichler AJ, Black CA, Kocan D (1980): Interchangeability of stress and amphetamine in sensitization. Science 207:329-331

Badiani A, Anagnostaras SG, Robinson TE (1995a): The development of sensitization to the psychomotor stimulant effects of amphetamine is enhanced in a novel environment. Psychopharmacol 117:443-452

Badiani A, Browman KE, Robinson TE (1995b): Influence of novel versus home environments on sensitization to the psychomotor stimulant effects of cocaine and amphetamine. Brain Res 674:291-298

Badiani A, Morano MI, Akil H, Robinson TE (1995c): Circulating adrenal hormones are not necessary for the development of sensitization to the psychomotor activating effects of amphetamine. Brain Res 673:13-24

Badiani A, Robinson TE (1994): Enhancement of amphetamine sensitization in a novel environment: the role of adrenal hormones. In Seredenin SB, Longo V, Gaviraghi G (eds), Biological Basis of Individual Sensitivity to Psychotropic Drugs. Edinburgh, Graffham Press, pp 231-241

Badiani A, Camp DM, Robinson TE (1997): Enduring enhancement of amphetamine sensitization by drug-associated environmental stimuli. J Pharmacol Exp Ther 282:787-794

Badiani A, Oates MM, Day HEW, Watson SJ, Akil H, Robinson TE (1998): Amphetamine-induced behavior, dopamine release, and c-fos mRNA expression: modulation by environmental novelty. J Neurosci (in press).

Browman KE, Badiani A, Robinson TE (1998a): The influence of environment on the induction of sensitization to the psychomotor activating effects of I.V. cocaine is dosedependent. Psychopharmacol 137:90-98

Browman KE, Badiani A, Robinson TE (1998b): Modulation of amphetamine sensitization by the circumstances surrounding drug administration: dose-effect relations. J Pharmacol Exp Ther, in press

Caine B, Lintz R, Koob GF (1993): Intravenous drug selfadministration techniques in animals. In Sahgal A (ed), Behavioral Neuroscience: A Practical Approach. Oxford, Oxford University Press, pp 11-143

Crombag HS, Badiani A., Robinson TE (1996): Signalled versus unsignalled intravenous amphetamine: large differences in the acute psychomotor response and sensitization. Brain Res 722:227-231

Friedman SB, Ader R. (1967): Adrenocortical response to novelty and noxious stimulation. Neuroendocrinol 2:209-212 
Graybiel AM, Moratalla R, Robertson, HA (1990): Amphetamine and cocaine induce drug specific activation of the c-fos gene in striosome-matrix compartments and limbic subdivisions of the striatum. Proc Natl Acad Sci USA 87:6912-6916

Hennessy MB (1991): Sensitization of the plasma corticosterone response to novel environments. Physiol Behav 50:1175-1179

Le Moal M (1995): Mesocorticolimbic dopaminergic neurons: functional and regulatory roles. In Kupfer DJ, Bloom FE (eds), Psychopharmacology: The Fourth Generation of Progress. New York, Raven Press, pp 695-704

Morimoto A, Nakamori T, Morimoto K, Tan N, Murakami N (1993): The central role of corticotrophin-releasing factor (CRF-41) in psychological stress in rats. J Physiol 460:221-229

Pert A, Post R, Weiss WS (1990): Conditioning as a critical determinant of sensitization induced by psychomotor stimulants. NIDA Res Monogr 97:208-241

Robinson TE, Badiani A (1994): The acute psychomotor response to amphetamine but not nucleus accumbens dopamine release is enhanced in a novel environment. Soc Neurosci Absts 20:830

Robinson TE, Becker JB (1986): Enduring changes in brain and behavior produced by chronic amphetamine administration: a review and evaluation of animal models of amphetamine psychosis. Brain Res Rev 11:157-198
Robinson TE, Berridge KC (1993): The neural basis of drug craving: an incentive-sensitization theory of addiction. Brain Res Rev 18:247-291

Robinson TE, Browman KE, Crombag HS, Badiani A (1998): Modulation of the induction and the expression of psychostimulant sensitization by the circumstances surrounding drug administration. Neurosci Biobehav Rev 22:347-354

Segal DS, Schuckit MA (1983): Animal models of stimulantinduced psychosis. In Creese I (ed), Stimulants: Neurochemical, Behavioral and Clinical Perspectives. New York, Raven Press, pp 131-167

Stewart J (1992): Conditioned stimulus control of the expression of sensitization of the behavioral activating effects of opiate and stimulant drugs. In Gormezano I, Wasserman EA (eds), Learning and Memory: The Behavioral and Biological Substrates. Hillsdale, NJ, Erlbaum, pp 129-151

Stewart J, Badiani A (1993): Tolerance and sensitization to the behavioral effects of drugs. Behav Pharmacol 4:289312

Weeks JR (1972): Long term intravenous infusions. In Meyers ED (ed), Methods in Psychobiology. London, Academic Press, pp 155-168

Wise RA, Bozarth, MA (1987): A psychomotor stimulant theory of addiction. Psychol Rev 94:469-492 